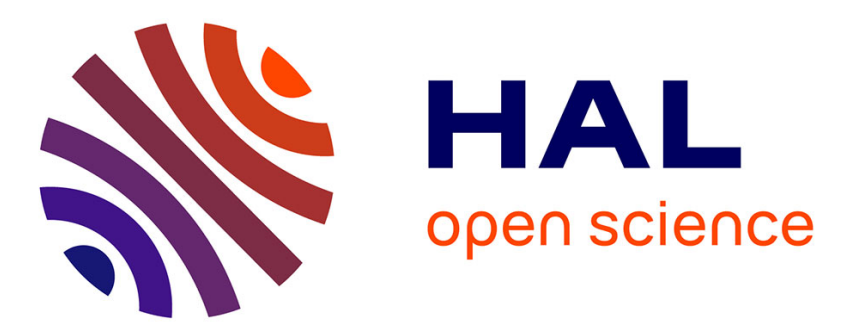

\title{
Numerical study on the improvement of flow distribution uniformity among parallel mini-channels
}

\author{
Cyril Pistoresi, Yilin Fan, Lingai Luo
}

\section{To cite this version:}

Cyril Pistoresi, Yilin Fan, Lingai Luo. Numerical study on the improvement of flow distribution uniformity among parallel mini-channels. Chemical Engineering and Processing: Process Intensification, 2015, 95, pp.63-71. 10.1016/j.cep.2015.05.014 . hal-03155799

\author{
HAL Id: hal-03155799 \\ https://hal.science/hal-03155799
}

Submitted on 2 Mar 2021

HAL is a multi-disciplinary open access archive for the deposit and dissemination of scientific research documents, whether they are published or not. The documents may come from teaching and research institutions in France or abroad, or from public or private research centers.
L'archive ouverte pluridisciplinaire HAL, est destinée au dépôt et à la diffusion de documents scientifiques de niveau recherche, publiés ou non, émanant des établissements d'enseignement et de recherche français ou étrangers, des laboratoires publics ou privés. 
Pistoresi, C., Fan, Y., \& Luo, L. (2015). Numerical study on the improvement of flow distribution uniformity among parallel mini-channels. Chemical Engineering and Processing: Process Intensification, 95, 63-71. https://doi.org/10.1016/j.cep.2015.05.014

\section{Numerical study on the improvement of flow distribution uniformity among parallel mini-channels}

${ }^{1}$ Laboratoire de Thermocinétique de Nantes, UMR CNRS 6607, Polytech' Nantes - Université de Nantes, La Chantrerie, Rue Christian Pauc, BP 50609, 44306 Nantes Cedex 03, France 3

\section{ABSTRACT}

Parallel micro or mini-channels are widely used in various devices of process and energy engineering 6 including micro-reactors, compact heat exchangers and fuel cells. Nevertheless, the flow maldistribution due to the improper design of distributor/collector is usually observed, leading to globally poor performances of these devices. The objective of this study is to optimize the shape of the distributor/collector pipes so as to achieve a uniform flow distribution among an array of parallel minichannels. A Z-type ladder fluid network with 10 mini-channels in parallel having square section is 1 introduced and investigated. Two methods are used to optimize the shape of distributor/collector pipes: an 2 optimized discrete stairway shape and a continuous tapered shape with an inclined angle varying from $0^{\circ}$ 3 to $30^{\circ}$. 3D-CFD simulations are carried out using the ANSYS FLUENT code. Numerical results obtained 4 show that a relatively uniform flow distribution may be reached by the discrete stairway shape or by the continuous tapered shape distributor/collector under very low flow-rate conditions. Larger inclined angle or fewer channels in parallel are favorable for more uniform flow distribution under higher flow-rate

\footnotetext{
*Corresponding author. Tel.: +33 240683167; Fax: +33 240683141. E-mail address: lingai.luo@univ-nantes.fr
} 
conditions. Nevertheless the distributor and the collector pipes occupy a large volume so that the entire device is less compact.

KEY WORDS: Process intensification; Mini-channels; Flow maldistribution; Shape optimization;

Distributor

\section{INTRODUCTION}

Chemical industries and process engineering are undergoing rapid changes in the $21^{\text {st }}$ century facing the challenges of climate change and energy shortage. Process Intensification (PI) that leads to smaller, less costly, cleaner, safer, higher productivity and more energy efficient technologies is proposed as a new paradigm of process engineering (Stankiewicz and Moulijn, 2002). Particularly, the innovative design of high yield processes or compact equipments has become one of the pressing industrial needs in recent years (Commenge and Falk, 2014).

One of the routes to PI is the use of equipments with locally miniaturized structures, i.e. micro or mini-channels (Charpentier, 2005; Luo, 2013; Commenge and Falk, 2014), because of their enhanced heat and mass transfer properties. Miniaturized process and energy equipments can either be heat exchangers (e.g. Fan and Luo, 2008; Fan et al., 2008; Khan and Fartaj, 2011), chemical mixers or reactors (e.g. Hessel et al., 2005; Illg et al., 2010; Guo et al., 2013), fuel cells (e.g. Sung, 2006; Jackson et al., 2014) or integrated multifunctional systems (e.g. Anxionnaz et al., 2008; Guo et al., 2014). Nevertheless, to obtain a comparable productivity with that of conventional equipment, a number of micro/mini-channels should be installed in parallel. This so-called numbering-up process is the key issue for large-scale industrial applications of these miniaturized devices (Al-Rawashdeh et al., 2012; Luo, 2013). Therefore, the fluid distribution uniformity among the parallel channels may play an important role on the global performance improvement of multi-channel equipments.

This is particularly true when multi-scale ladder-type fluid networks (Figure 1a) are involved (Saber et al. 2010; Commenge et al. 2011). In order to achieve uniform flow distribution among all parallel channels in the network, the first and essential step is the design of an optimized two-scale elementary Z-type ladder circuit, as shown in Figure 1b. In this elementary fluidic circuit, the single inlet port and 
single outlet port are located on opposite sides of the bundle of parallel cross-channels, meaning that the flow direction is the same in the distributor and the collector pipes. All cross-channels are assumed to have the same geometrical characteristics so that the passage-to-passage maldistribution may be considered as negligible (Rebrov et al., 2011). On the contrary, the improper design of fluid distributor/collector pipes is the main cause of flow maldistribution among the parallel cross-channels.

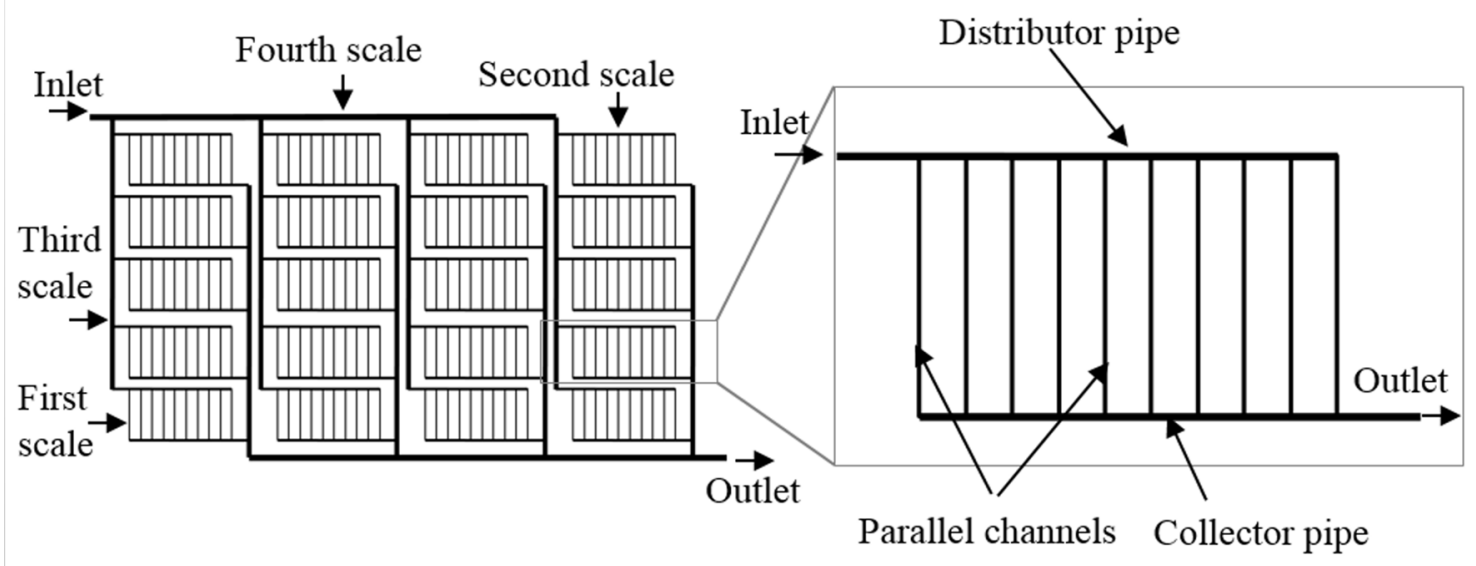

Figure 1. Multi-scale fluidic network (a) and elementary Z-type ladder circuit (b).

Many studies have then been focused on how to improve the flow distribution uniformity of the elemental Z-type ladder circuit. It is reported that a relatively uniform distribution may only be approached by making the hydraulic resistance of cross-channels much larger than that of the distributor and collector pipes if the latter have a uniform profile (e.g. Saber et al., 2009; Tondeur et al., 2011a). This usually implies that the distributor and collector pipes are large and encumbering, which is clearly unfavorable for miniaturized devices. Instead of the uniform profile (rectangular or cylinder shape) of the distributor and collector, alternative shapes were proposed, such as triangular or trapezoidal-type (e.g. Kim et al., 1995; Commenge et al., 2002; Pan et al., 2009; Renault et al., 2011) or curvatured shape (e.g. Pan et al., 2008; Cho et al., 2010; Jackson et al., 2014). In particular,

72 Tondeur et al. (2011b) proposed to "taper" the profile of distributor and collector pipes in a discrete 73 stairway so that the flow resistances vary linearly with position, which may offer a uniform flow 74 distribution among the parallel cross-channels. Analytical scaling relations were established based on 
the assumptions of Poiseuille flow and negligible singular losses (pressure losses due to divergent/convergent branching). However, no numerical or experimental work has been performed to evaluate the validity and the effective range of this analytical model. The sensitivity of the flow distribution characteristics subjected to different working conditions (e.g. different flow-rate) has not yet been reported.

In the present work, the flow distribution properties on a typical Z-type elemental ladder circuit are systematically investigated. We will first describe the design of a mini-channel array with integrated discrete stairway shape distributor and collector pipes based on the scaling relations proposed by Tondeur et al. (2011b). In addition, a continuous model with progressive dimension reduction (or increase) for the distributor pipe (or the collector pipe) is also introduced for comparison. Then, computational fluid dynamics (CFD) simulation results for both models will be reported, under a variety of flow-rate conditions. After that influences of some design parameters including the inclined angle and the number of parallel channels will also be discussed. Finally, main conclusions and perspectives will be summarized.

\section{GEOMETRY AND NUMERICAL PARAMETERS}

In this section, the design of parallel mini-channel array with integrated distributor/collector pipes based on two models, i.e. the discrete stairway model and the continuous tapered model will be briefly described. The CFD simulation tool and the controlling parameters will be introduced as well.

\subsection{Geometry of the tested mini-channel array}

Figure 2 shows a representative schematic view of Z-type elemental ladder fluid circuit. The 3D fluid domain consists of 3 sections: inlet distributor pipe, parallel mini-channel array, and outlet collector pipe. This Z-type elemental ladder network is widely used in different applications such as catalytic reactors, solar receivers, heat exchanger plates, elements of fuel cells, electrochemical microreactors, cooling network of heat sinks, or other process components. For the convenience of potential fabrication, the entire fluidic circuit has the identical channel depth $(e=1 \mathrm{~mm})$. There are 10 parallel 
101 straight channels $(N=10)$ of identical length $\left(L_{c h}=20 \mathrm{~mm}\right)$, width $\left(w_{c h}=1 \mathrm{~mm}\right)$ and depth $(e=1 \mathrm{~mm})$.

102 They are evenly spaced $\left(l_{x}=2 \mathrm{~mm}\right)$ between the axis of one channel and another. Square cross-section

103 is used for the channels because it is adapted for future experimental visualization of the internal flow

104 using digital camera and optical tracers. Here we introduced a millimetric design (hydraulic diameter

105 of channels being $1 \mathrm{~mm}$ ) because it may have comparable mixing or heat transfer performances with

106 respect to micro-channels but with higher throughput and lower pressure loss (Luo et al., 2007; Guo et

107 al., 2013). For the convenience of description, these mini-channels are indexed by $k$ from 1 to $N$ from

108 left to right. When a pressure difference is applied between inlet and outlet to cause flow, it will passes

109 through the distributor pipe, the parallel channels and the collector pipe subsequently to reach the

110 outlet. The flow-rate in $k$ th mini-channel is notated as $q_{k}$.

111

(a) Distributor pipe

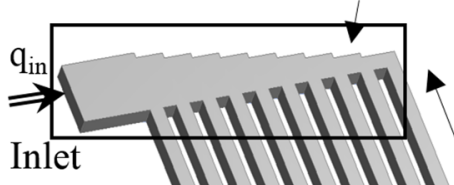

11110

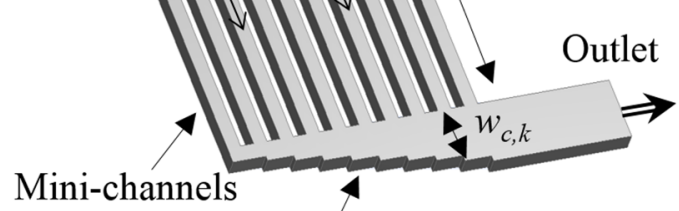

Collector pipe (b)

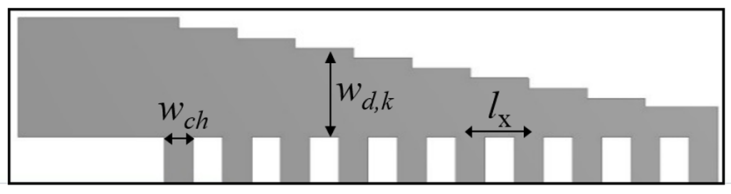

(c)

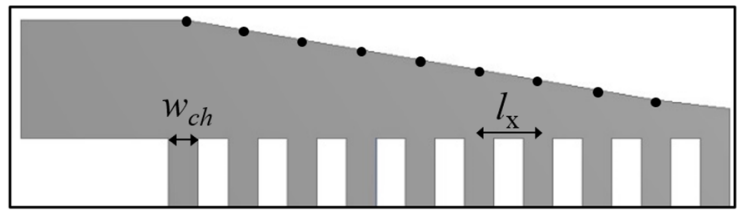

Figure 2. Geometry of the tested Z-type ladder. (a) mini-channel array; (b) discrete stairway type

The flow maldistribution is quantified by two parameters: the relative flow-rate deviation $\sigma_{k}$ and the maldistribution factor MF.

$$
\sigma_{k}=\frac{q_{k}-\bar{q}}{\bar{q}}
$$

$$
\mathrm{MF}=\sqrt{\frac{1}{N-1} \sum_{k=1}^{N}\left(\frac{q_{k}-\bar{q}}{\bar{q}}\right)^{2}}
$$


where $\bar{q}$ is the mean flow-rate between parallel outlet channels.

$$
\bar{q}=\frac{\sum_{k=1}^{N} q_{k}}{N}
$$

122 The value of $\sigma_{k}$ indicates the departure of the flow-rate in an individual channel $k$ from the mean value

123 whereas the value of MF indicates the overall flow maldistribution of the whole fluidic network.

124 Uniform flow distribution is achieved when values of $\sigma_{k}$ and MF approach 0.

125

126

134 where $R_{d, k}$ and $R_{c, k}$ are the flow resistance of $k$ th segment of the distributor pipe or the collector pipe, 135 respectively. Using this scaling relation, a Z-type fluid circuit with uniform cross-flow distribution can 136 be designed. One possible example is schematically shown in Figure 3, where the subscripts $d$, c, and ch represent the distributor, the collector and the cross-channel, respectively. The mass and pressure

138 conservations can be easily verified while keeping the cross flow-rate all equal $\left(q_{k}=q_{c h}\right)$. 
139

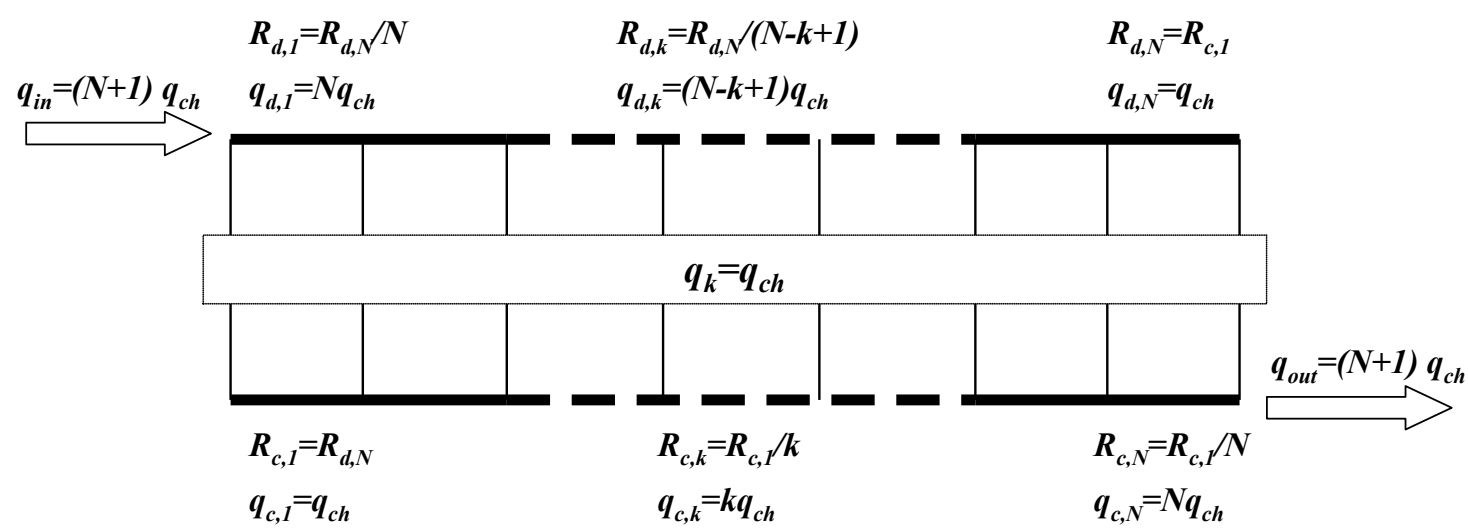

140 Figure 3. Flow resistance distribution for uniform flow distribution among parallel channels. Modified from

143 The dimension of each segment of distributor/collector pipes can then be determined by supposing

144 Poisseuille flow in straight channel with rectangular cross-section. The flow resistance in $k$ th segment

145 of the distributor pipe $R_{d, k}$ may be expressed as (White, 2003):

$$
R_{d, k}=\frac{1}{2} \rho f_{d, k} \frac{L_{d, k}}{D_{h, k} e w_{d, k}} u_{d, k}
$$

where $\rho$ is the density of fluid, $L_{d, k}$ the length of $k$ th segment, $e$ the depth of channels $(1 \mathrm{~mm}), w_{d, k}$ the width of $k$ th segment to be determined and $u_{d, k}$ the fluid velocity in the $k$ th segment. $D_{h, k}$ is the hydraulic diameter for rectangular cross-section and $f_{d, k}$ the friction factor for a straight channel.

$$
\begin{gathered}
D_{h, k}=\frac{2 e w_{d, k}}{e+w_{d, k}} \\
f_{d, k}=\frac{F_{d, k}}{\operatorname{Re}_{d, k}}=\frac{F_{d, k} \mu}{\rho u_{d, k} D_{h, k}}
\end{gathered}
$$

152 where Re is the Reynolds number, $\mu$ the viscosity of the fluid and $F_{d, k}$ the form factor. The values of

$153 F_{d, k}$ for rectangular cross-section channels depend on the ratio of channel depth and width

$154\left(e / w_{d, k}\right)$. Eq. (8) presents the polynomial fitting correlation for $F_{d, k}$, based on the data provided 155 from (White, 2003). 


$$
F_{d, k}=-50.4\left(\frac{e}{w_{d, k}}\right)^{3}+132.7\left(\frac{e}{w_{d, k}}\right)^{2}-121.2\left(\frac{e}{w_{d, k}}\right)+95.7
$$

Regrouping Eqs.5-7, one may obtain:

$$
R_{d, k}=F_{d, k} \mu L_{d, k} \frac{\left(e+w_{d, k}\right)^{2}}{8 e^{3} w_{d ; k}^{3}}
$$

It may be verified that the flow resistances for segments of collector pipe share the same expression as Eq. 9, by replacing the subscript $d$ with $c$. By letting $w_{d, N}=w_{c, l}=w_{c h}=1 \mathrm{~mm}$, the other values of $w_{d, k}$ and $w_{c, k}$ can then be derived using Eqs. 4, 8 and 9, as listed in Table 1.

Table 1. Widths for the segments of distributor/collector pipes (unit: $\mathrm{mm}$ )

\begin{tabular}{cccccccccc}
\hline$w_{d, 1}$ & $w_{d, 2}$ & $w_{d, 3}$ & $w_{d, 4}$ & $w_{d, 5}$ & $w_{d, 6}$ & $w_{d, 7}$ & $w_{d, 8}$ & $w_{d, 9}$ & $w_{d, 10}$ \\
$w_{c, 10}$ & $w_{c, 9}$ & $w_{c, 8}$ & $w_{c, 7}$ & $w_{c, 6}$ & $w_{c, 5}$ & $w_{c, 4}$ & $w_{c, 3}$ & $w_{c, 2}$ & $w_{c, 1}$ \\
\hline 4.01 & 3.66 & 3.30 & 2.99 & 2.65 & 2.31 & 1.97 & 1.63 & 1.29 & 1.00 \\
\hline
\end{tabular}

Figure $2 \mathrm{~b}$ illustrates the discrete stairway model of the Z-type ladder fluidic circuit, designed according to the morphology presented in Figure 3. Note that a continuous tapered model may also be designed, as shown in Figure 2c, by replacing the stairs by linear profiles from point to point. It may be observed that the linearization leads to an approximate trapezoidal shape for the distributor and collector, with an inclined angle $(\theta)$ of about $11.3^{\circ}$. This value is close to the theoretical optimal angle $\left(10.46^{\circ}\right)$ proposed by the model of Renault et al. (2012). The comparison between two models, i.e. the discrete stairway model and the continuous tapered model on their flow distribution properties and the related pressure drop is interesting but never attempted. Numerical tests were then performed for both models for comparison.

\subsection{Simulation parameters}

175 In this study, geometries and meshes were generated using different modules of ANSYS Workbench

176 12.1. Note that due to symmetrical character of the network in the direction of the depth, half of the

177 body had been considered in the analysis. Fluent code V.12.1.4 was used to solve Navier-Stokes 178 equations by finite volume methods. The equation for conservation of mass or continuity is: 


$$
\frac{\partial \rho}{\partial t}+\nabla \cdot(\rho \vec{u})=0
$$

180

The momentum conservation equation:

$$
\frac{\partial}{\partial t}(\rho \vec{u})+\nabla \cdot(\rho \vec{u} \vec{u})=-\nabla p+\nabla \cdot(\Pi)+\rho \vec{g}+\vec{F}
$$

where $\vec{u}$ is the velocity, $p$ is the static pressure, $\rho \vec{g}$ and $\vec{F}$ are the gravitational body force and external body forces, $\Pi$ is the stress tensor which is given by:

$$
\Pi=\mu\left[\left(\nabla \vec{u}+\nabla \vec{u}^{\mathrm{T}}\right)-\frac{2}{3} \nabla \cdot \vec{u} I\right]
$$

where $\mu$ is the molecular viscosity, $I$ is the unit tensor.

Pure water at constant temperature of $293 \mathrm{~K}$ was chosen as working fluid (density $\rho=998.29 \mathrm{~kg} \cdot \mathrm{m}^{-3}$ and viscosity $\left.\mu=1.003 \times 10^{-3} \mathrm{~kg} \cdot \mathrm{m}^{-1} \cdot \mathrm{s}^{-1}\right)$. The operational pressure was fixed at $101325 \mathrm{~Pa}$. In this study, simulations were performed under steady state, incompressible and isothermal condition without heat transfer. For simplification, gravity effect and viscous heating were neglected.

Velocity inlet normal to the surface was set as the boundary condition for the inlet. Four inlet velocity conditions $\left(U_{\text {in }}\right)$ were tested: $1.25 \times 10^{-3} \mathrm{~m} \cdot \mathrm{s}^{-1} ; 1.25 \times 10^{-2} \mathrm{~m} \cdot \mathrm{s}^{-1} ; 1.25 \times 10^{-1} \mathrm{~m} \cdot \mathrm{s}^{-1}$ and $1.25 \mathrm{~m} \cdot \mathrm{s}^{-1}$, corresponding to a value of mean channel Reynolds number $\left(\mathrm{Re}_{\mathrm{ch}}\right)$ of $1.25,1.25 \times 10^{1}, 1.25 \times 10^{2}$ and $1.25 \times 10^{3}$, respectively. The boundary condition of outlet was set as pressure-outlet with zero static pressure. Adiabatic wall condition was applied and no slip occurred at the wall.

Laminar flow model was used under very low velocity conditions while $k-\varepsilon$ Re-Normalized Group ( $k-\varepsilon$ $\underline{\mathrm{RNG}}$ ) was used for higher velocity conditions because micro turbulences and local vortex may exist. For the pressure-velocity coupling, standard SIMPLE method was used. For discretization, standard method was chosen for pressure and first-order upwind differentiation for momentum. The solution was considered to be converged when the flow-rate at each channel and the inlet static pressure were constant from one iteration to the next (less than $0.5 \%$ variation) and the normalized residuals of all monitoring parameters were lower than the order of magnitude of $10^{-6}$. 


\subsection{Grid independence study}

203 A grid independence study was performed using three structured meshes with different resolutions: 204 coarse mesh (10 segments per millimeter; 0.18 million elements); medium mesh (20 segments per 205 millimeter; 1.65 million elements) and refined mesh (30 segments per millimeter; 5.28 million 206 elements). Simulation results with an inlet velocity of $1.25 \times 10^{-1} \mathrm{~m} \cdot \mathrm{s}^{-1}$ (mean $\operatorname{Re}_{\mathrm{ch}}=1.25 \times 10^{2}$ ) indicated 207 a difference of $3.7 \%$ on the inlet pressure between the coarse mesh and the refined mesh, and of $0.9 \%$ 208 between medium mesh and refined mesh. Mass flow-rates in each mini-channel were also compared, 209 showing a maximum difference of $2.6 \%$ between the coarse mesh and the refined mesh, and of $1.3 \%$ 210 between the medium mesh and the refined mesh. Hence, the medium mesh was selected as a 211 compromise between the calculation time and the precision.

\section{SIMULATION RESULTS}

214 Figure 4 shows the contour of velocity magnitude on the mid-depth surface (symmetry) of the Z-type 215 ladder circuit, under different inlet velocity conditions. Simulation results for the discrete stairway 216 model are presented on the left side of Figure 4 while those for the continuous tapered model are 217 shown on the right side. It can be observed on Figure $4 \mathrm{a}$ and $4 \mathrm{~b}$ that for relatively low inlet velocity 218 conditions $\left(U_{\text {in }}=1.25 \times 10^{-3} \mathrm{~m} \cdot \mathrm{s}^{-1}\right.$; mean $\operatorname{Re}_{\mathrm{ch}}=1.25$ and $U_{\text {in }}=1.25 \times 10^{-2} \mathrm{~m} \cdot \mathrm{s}^{-1}$; mean $\left.\operatorname{Re}_{\mathrm{ch}}=1.25 \times 10^{1}\right)$, both 219 models could provide a relatively uniform flow distribution among the 10 parallel mini-channels. It seems that the velocity profiles in the distributor pipe and in the collector pipe are regular and symmetric, implying that the flow patterns are rather laminar. The impact of singularity losses in converging or diverging bifurcations on the flow distribution uniformity is not significant. 


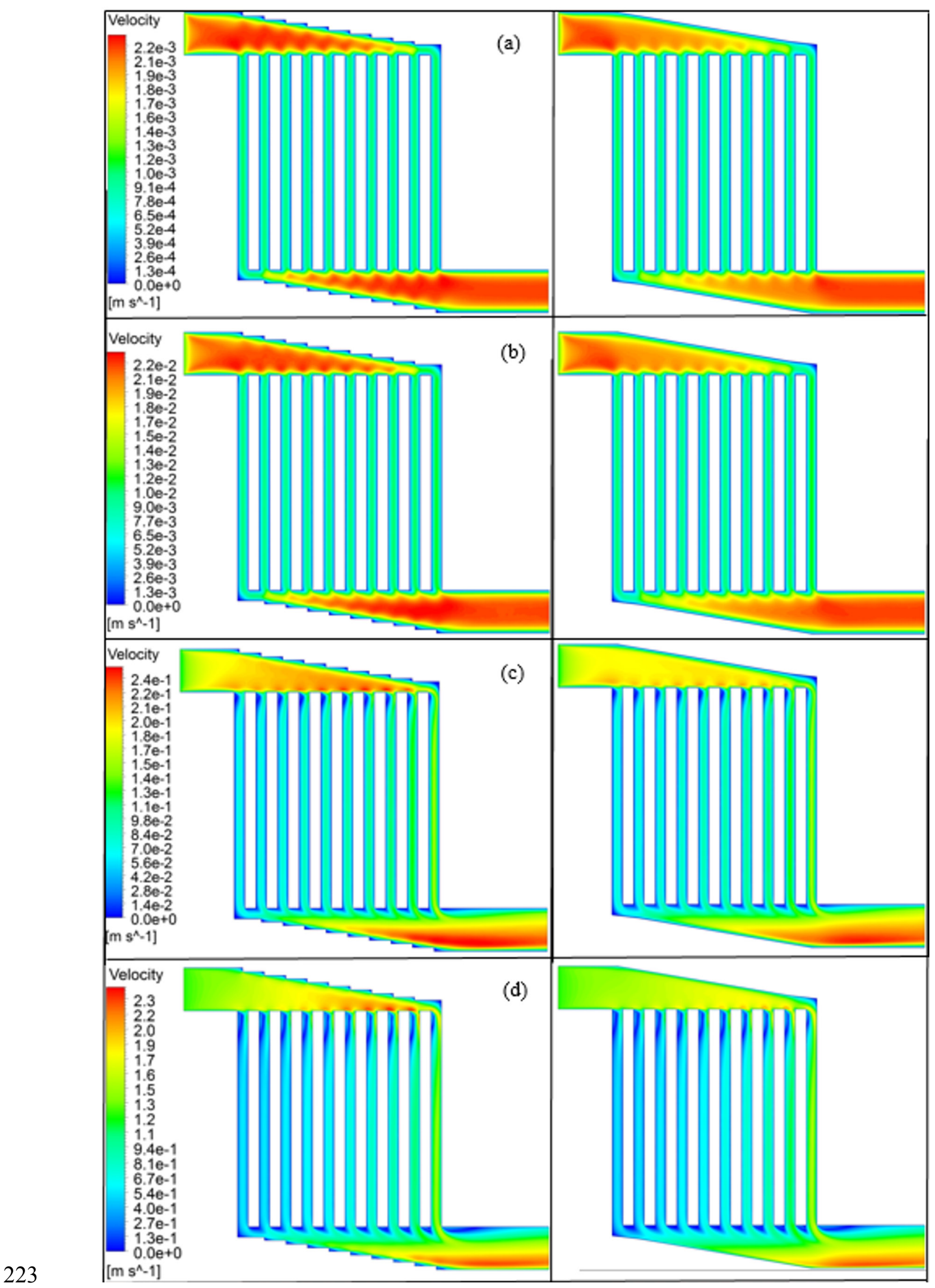

Figure 4. Velocity profiles for the discrete stairway model and for the continuous tapered model. (a) $U_{i n}=1.25 \times 10^{-3} \mathrm{~m} . \mathrm{s}^{-1}$ (mean $\operatorname{Re}_{\mathrm{ch}}=1.25$ ); (b) $U_{i n}=1.25 \times 10^{-2} \mathrm{~m} . \mathrm{s}^{-1}$ (mean $\left.\mathrm{Re}_{\mathrm{ch}}=1.25 \times 10^{1}\right)$; (c) $U_{\text {in }}=1.25 \times 10^{-1} \mathrm{~m} . \mathrm{s}^{-1}$ (mean $\mathrm{Re}_{\mathrm{ch}}=1.25 \times 10^{2}$ ); (d) $U_{i n}=1.25 \mathrm{~m} \cdot \mathrm{s}^{-1}$ (mean $\mathrm{Re}_{\mathrm{ch}}=1.25 \times 10^{3}$ ) 
On the contrary for relatively high inlet velocity conditions $\left(U_{i n}=1.25 \times 10^{-1} \mathrm{~m} \cdot \mathrm{s}^{-1}\right.$; mean $\operatorname{Re}_{\mathrm{ch}}=1.25 \times 10^{2}$ and $U_{i n}=1.25 \mathrm{~m} . \mathrm{s}^{-1}$; mean $\mathrm{Re}_{\mathrm{ch}}=1.25 \times 10^{3}$ ), flow maldistribution among parallel channels is obvious, as shown on Figure $4 \mathrm{c}$ and $4 \mathrm{~d}$. This is mainly due to the stronger inertial force at the higher velocity so that the fluid enters the right most channels preferentially. Dead volumes may easily be observed at 231 the entrance zone and outside the exit port of each cross-channel. Small vortex and micro-turbulences 232 may also be observed and the velocity profiles in the distributor and in the collector pipes are no 233 longer symmetrical. These results indicate that more appropriate scaling relations should be 234 developed, taking the internal terms and the singular effects into account. Some recent efforts may be found in references (Midoux and Tondeur, 2014; 2015) for U-type ladder circuits.

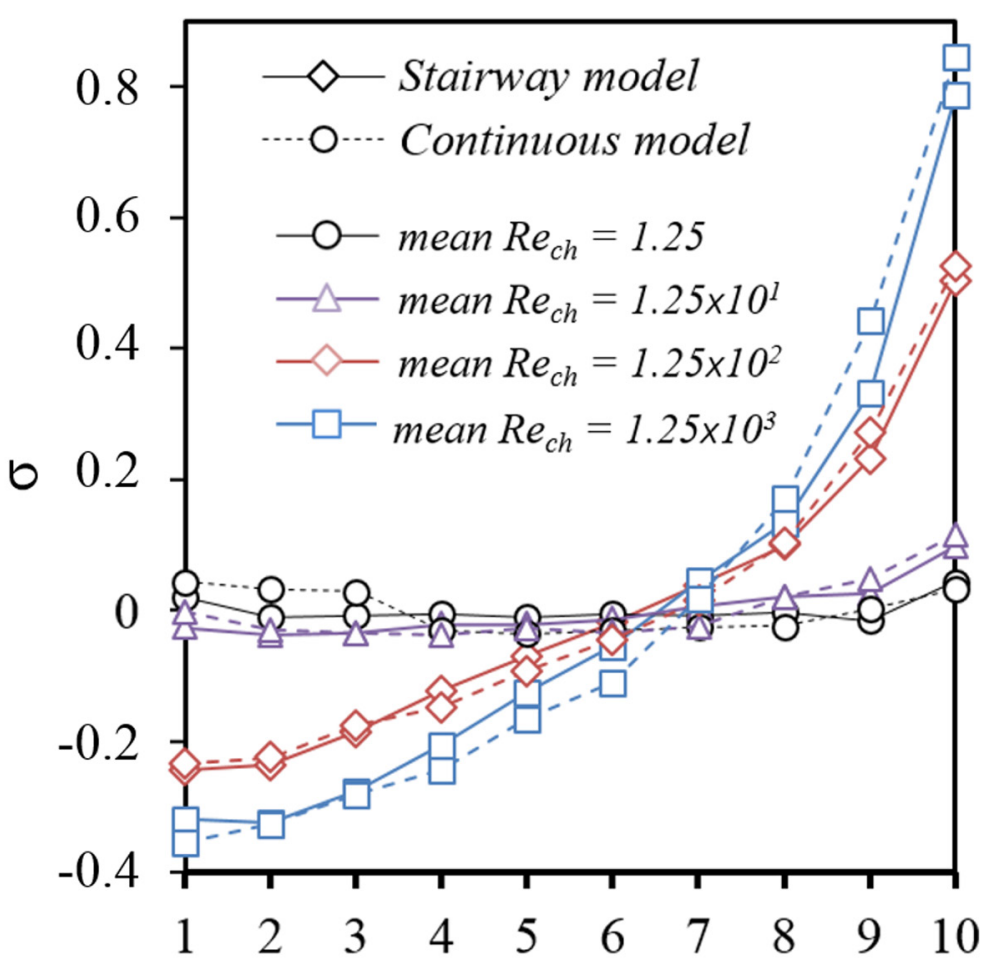

\section{Serial number of channels}

Figure 5. Relative flow-rate deviation $(\sigma)$ of parallel channels for different inlet velocity conditions

240 The increase of flow maldistribution with the increasing inlet velocity may be quantitatively shown in

241 Figure 5, which presents the relative flow-rate deviation $\sigma$ of each channel for different inlet velocity 242 conditions. For inlet velocity $U_{i n}=1.25 \times 10^{-2} \mathrm{~m} \cdot \mathrm{s}^{-1}$ (mean $\operatorname{Re}_{\mathrm{ch}}=1.25 \times 10^{1}$ ), the maximum flow-rate 
243 deviation is about 0.098 and 0.117 for discrete stairway model and for continuous tapered model, 244 respectively, implying an acceptable flow distribution uniformity. However, the maximum value of $\sigma$ 245 rapidly increases to 0.78 (stairway model) and 0.84 (continuous model) for inlet velocity $U_{i n}=1.25 \mathrm{~m} . \mathrm{s}^{-}$

$246{ }^{1}$ (mean $\left.\operatorname{Re}_{\mathrm{ch}}=1.25 \times 10^{3}\right)$, implying significant flow maldistribution.

247 Table 2 gives a comparison on the flow distribution uniformity and inlet/outlet pressure loss of the 248 circuit between the discrete stairway model and the continuous tapered model, for different inlet 249 velocity conditions. Very similar performances may be observed. For the same inlet velocity 250 condition, the discrete stairway model may provide slightly better flow distribution uniformity with 251 respect to the continuous tapered model, but generate higher pressure losses. Especially for inlet 252 velocity $U_{i n}=1.25 \mathrm{~m} \cdot \mathrm{s}^{-1}$ (mean $\mathrm{Re}_{\mathrm{ch}}=1.25 \times 10^{3}$ ), the value of pressure loss is $5.46 \mathrm{kPa}$ for the discrete 253 stairway model, $14.5 \%$ higher than that of the continuous tapered model (4.61 $\mathrm{kPa})$ while the values of $254 \quad$ MF are almost the same (0.387 vs. 0.395$)$.

Table 2. Comparison of pressure loss $(\Delta p)$ and maldistribution factor (MF) between two models

\begin{tabular}{|c|c|c|c|c|c|}
\hline & & \multicolumn{3}{|c|}{$\Delta P[\mathrm{~Pa}]$} & \multirow{2}{*}{$\frac{\text { MF [-] }}{\text { Continuous }}$} \\
\hline $\begin{array}{c}\text { Inlet velocity } \\
{\left[\mathrm{m} \cdot \mathrm{s}^{-1}\right]}\end{array}$ & $\begin{array}{c}\text { Mean } \operatorname{Re}_{\mathrm{ch}} \\
{[-]}\end{array}$ & Stairway & Continuous & Stairway & \\
\hline $1.25 \times 10^{-3}$ & 1.25 & $9.20 \times 10^{-1}$ & $8.80 \times 10^{-1}$ & $1.82 \times 10^{-2}$ & $2.99 \times 10^{-2}$ \\
\hline $1.25 \times 10^{-2}$ & $1.25 \times 10^{1}$ & 9.48 & 9.05 & $4.11 \times 10^{-2}$ & $5.44 \times 10^{-2}$ \\
\hline $1.25 \times 10^{-1}$ & $1.25 \times 10^{2}$ & $1.29 \times 10^{2}$ & $1.19 \times 10^{2}$ & $2.33 \times 10^{-1}$ & $2.43 \times 10^{-1}$ \\
\hline 1.25 & $1.25 \times 10^{3}$ & $5.46 \times 10^{3}$ & $4.61 \times 10^{3}$ & $3.87 \times 10^{-1}$ & $3.95 \times 10^{-1}$ \\
\hline
\end{tabular}

258 As a short conclusion, the discrete stairway model could provide relatively uniform flow distribution 259 only under low flow-rate conditions (e.g. $U_{\text {in }}<1.25 \times 10^{-2} \mathrm{~m} \cdot \mathrm{s}^{-1}$; mean $\mathrm{Re}_{\mathrm{ch}}<1.25 \times 10^{1}$ ). The flow 260 maldistribution observed at higher flow-rate conditions is mainly due to the departure from the ideal 261 flow pattern (pure Poiseuille flow, neglecting the inertial terms, neglecting the singular effects). The 262 continuous tapered model shows comparable performances to discrete stairway model, but may be 263 more favorable in terms of lower pressure loss under higher flow-rate conditions. However, uniform 264 flow distribution can no longer be guaranteed. 


\section{EFFECTS OF DESIGN PARAMETERS}

267 In this section, the effects of some design parameters on the flow distribution uniformity will be tested

268 and reported. We focus on the continuous tapered model because it may provide comparable flow 269 distribution uniformity with respect to the discrete stairway model but with relatively lower pressure 270 loss and easier to be fabricated. Two design parameters will be studied: the inclined angle $(\theta)$ of the 271 distributor/collector pipes and the total number $(N)$ of parallel mini-channels.

\subsection{Effects of the inclined angle}

273 Numerical simulations were performed for the Z-type ladder circuit with the inclined angle $(\theta)$ for the 274 distributor/collector pipes varying from $0^{\circ}$ to $30^{\circ}$, under four different inlet velocity conditions (mean $275 \operatorname{Re}_{\mathrm{ch}}$ varying between 1.25 and $\left.1.25 \times 10^{3}\right)$. The inclined angle $\theta=0^{\circ}$ shows a classic rectangular shape 276 of distributor/collector pipes while other values of $\theta$ implies a trapezoidal or near triangular shape.

277 Other geometrical dimensions are kept as the same as the one tested in the above section.

278 Figure 6 shows the velocity profiles in the Z-type ladder circuit with different inclined angles for the 279 distributor/collector pipes, for $U_{i n}=1.25 \times 10^{-2} \mathrm{~m} \cdot \mathrm{s}^{-1}$ (mean $\mathrm{Re}_{\mathrm{ch}}=1.25 \times 10^{1}$ ). It may be observed that the 280 flow always goes preferentially into the rightmost channels of the circuit, implying that at this inlet 281 velocity, the inertial effect of fluid flow is already significant. It may also be observed that the higher 282 the value of $\theta$, the more uniform flow distribution may be achieved. However, this implies that the 283 entire flow circuit becomes less compact, i.e. the distributor and collector pipes occupy a large 284 volume. 


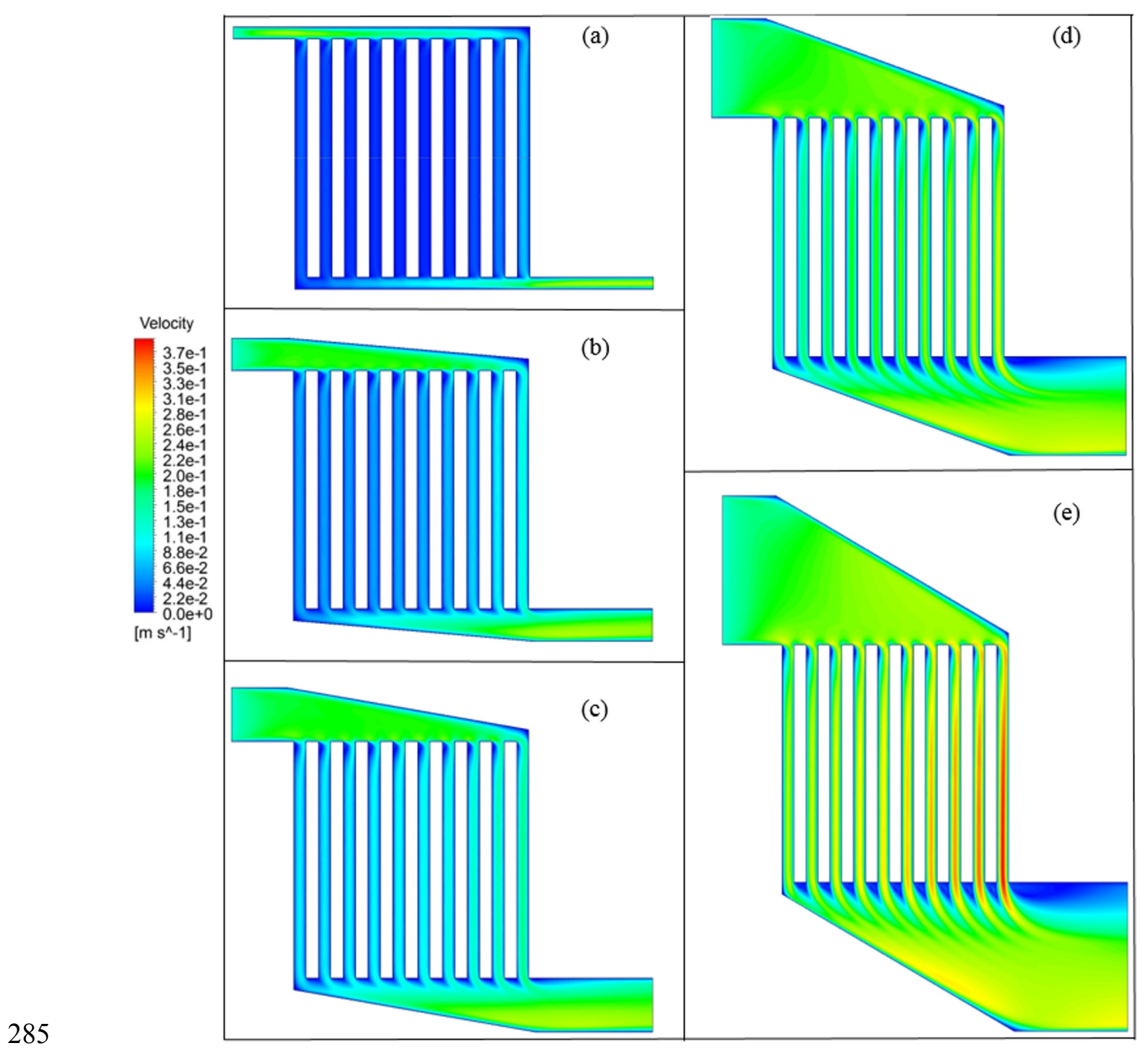

286 Figure 6. Velocity profiles in the Z-type ladder circuit for $U_{i n}=1.25 \times 10^{-1} \mathrm{~m} \cdot \mathrm{s}^{-1}$ (mean $\operatorname{Re}_{\mathrm{ch}}=1.25 \times 10^{2}$ ). (a) $\theta=0^{\circ}$;

(b) $\theta=5^{\circ}$; (c) $\theta=10^{\circ}$; (d) $\theta=20^{\circ}$; (e) $\theta=30^{\circ}$

289 Figure 7 indicates the influences of the inclined angle $(\theta)$ on the flow distribution uniformity of the 290 ladder circuit, under different inlet velocity conditions. For a certain inclined angle, the flow 291 maldistribution increases with increasing inlet velocity, as already reported above. For a same inlet 292 velocity, larger inclined angle leads to more uniform flow distribution. However, the improvement 293 becomes less and less notable when $\theta$ value increases. These results are in accordance with those of 294 Pan et al. (2009), who reported that for symmetrical manifold structures velocity distribution becomes 295 more uniform with larger radius of inlet/outlet. 


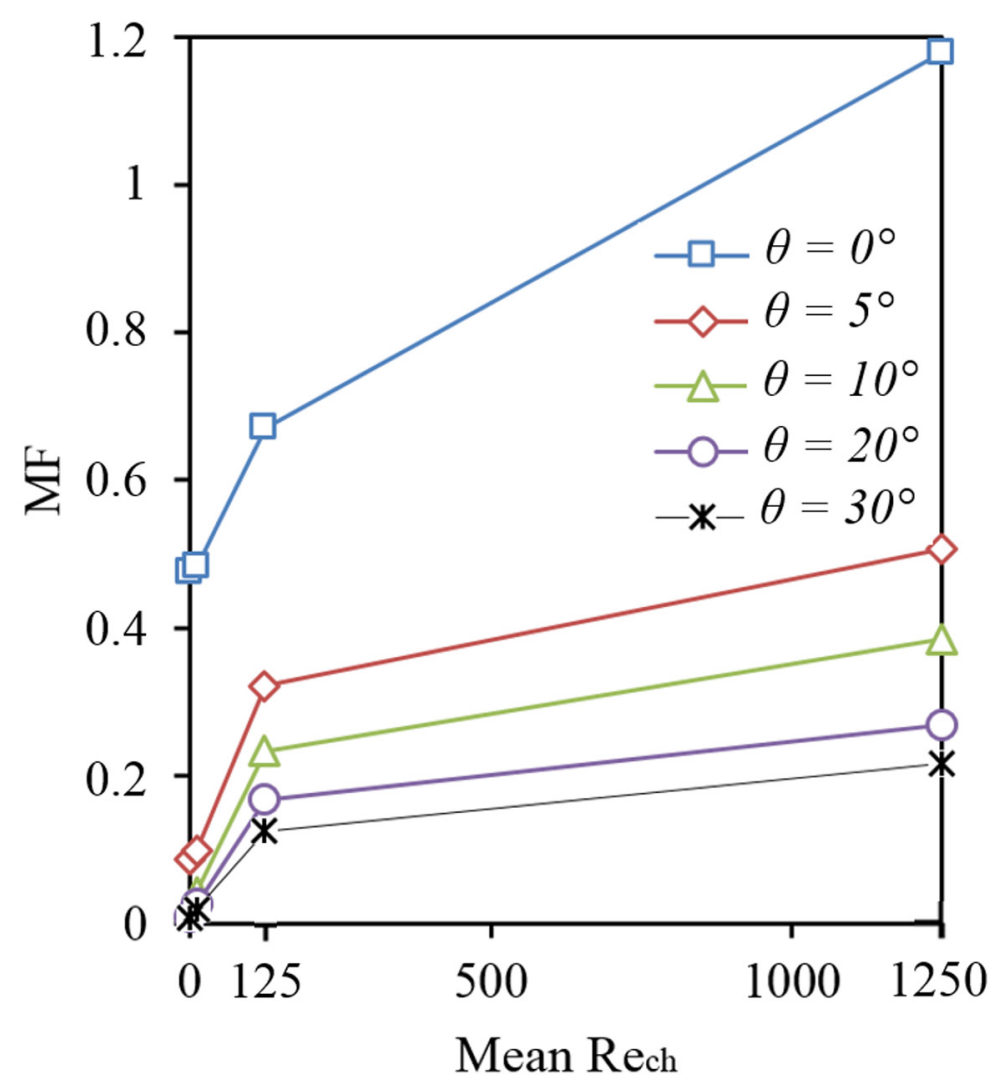

297 Figure 7. Influences of inclined angle $(\theta)$ on the flow distribution uniformity (MF) under different inlet velocity 298 conditions

301 3D-CFD simulations were realized on Z-type ladder circuit with number of mini-channels of 5, 10 and 30220 , while the inclined angle of the distributor/collector pipes was fixed at $30^{\circ}$, as shown in Figure 8. 303 This is for the purpose of highlighting the influence of the number of mini-channels on the flow 304 distribution uniformity. 

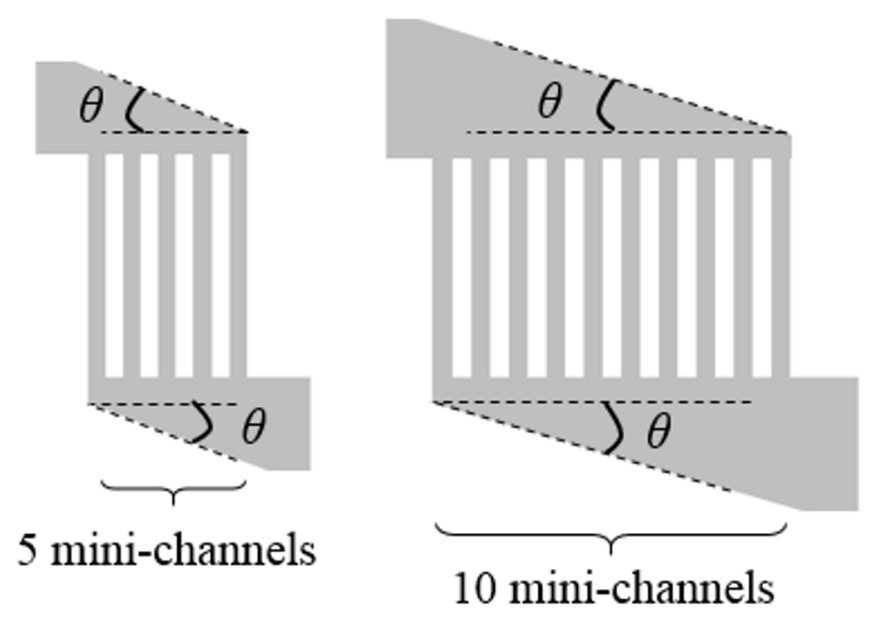

\section{5 mini-channels}

\section{0 mini-channels}

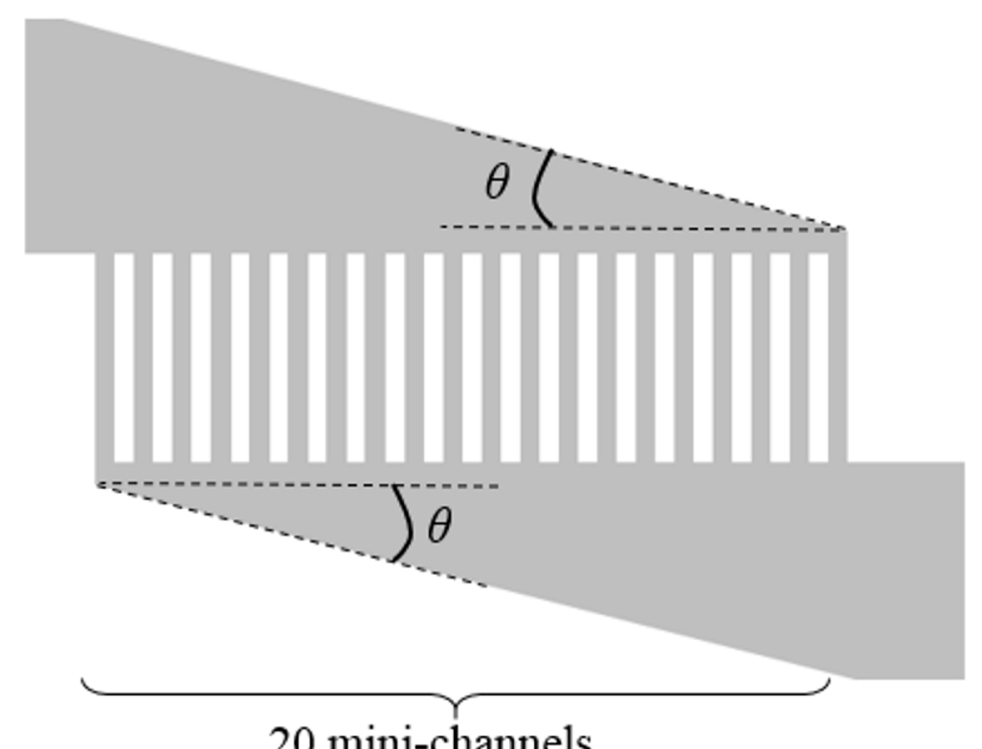

Figure 8. Geometries of ladder circuit tested with different number of mini-channels in parallel

308 Figure 9 shows the evolution of maldistribution factor (MF) as a function of the number of mini309 channels under four inlet velocity conditions studied. It may be observed that the difference on the 310 flow distribution uniformity for different $N$ cases is relatively very small under low inlet velocity 311 conditions (e.g. $U_{i n}<1.25 \times 10^{-2} \mathrm{~m} . \mathrm{s}^{-1}$; mean $\mathrm{Re}_{\mathrm{ch}}=1.25 \times 10^{1}$ ). However, the value of $\mathrm{MF}$ increases 312 rapidly with increasing $N$ number under high velocity conditions. For a inlet velocity $U_{\text {in }}=1.25 \mathrm{~m} \cdot \mathrm{s}^{-1}$ 313 (mean $\operatorname{Re}_{\mathrm{ch}}=1.25 \times 10^{3}$ ), the value of the MF increases from 0.100 for 5 channels case, to 0.217 for 10 314 channels case, and finally reaches 0.229 for 20 channels case. Generally speaking, it will be easier to 315 achieve uniform flow distribution when fewer sub-streams should be formed $($ small $N)$. 


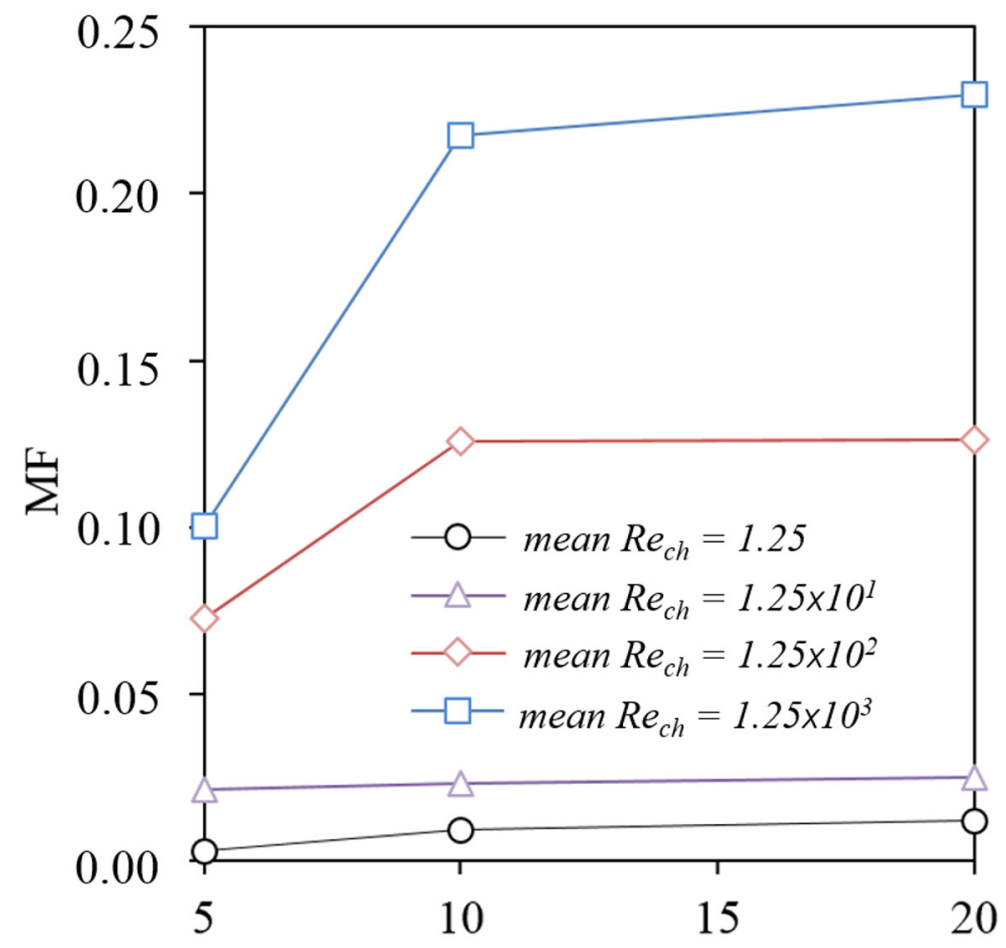

\section{Overall number of parallel channels $N$}

Figure 9. Influences of the number of parallel channels $(N)$ on the flow distribution uniformity (MF) under

\section{CONCLUSION AND PERSPECTIVES}

321 This paper presents a numerical study on the flow distribution characteristics of a Z-type ladder circuit

322 having 10 mini-channels in parallel. The validity and the effective range of the discrete stairway model 323 and the continuous tapered model for the design of distributor/collector pipes are discussed. The 324 effects of inclined angle and the number of parallel mini-channels on the distribution uniformity are 325 also analyzed. Based on the results presented above, the following conclusions may be reached.

- The discrete stairway model could provide relatively uniform flow distribution under low flow-rate conditions (e.g. $U_{\text {in }}<1.25 \times 10^{-2} \mathrm{~m}^{-1}{ }^{-1}$; mean $\operatorname{Re}_{\mathrm{ch}}<1.25 \times 10^{1}$ ). For higher flow-rate conditions, significant flow maldistribution seems inevitable.

- The continuous tapered model by linearizing the stairways may provide comparable flow distribution uniformity regarding the discrete stairway model, but may be more favorable in terms of lower pressure loss under higher flow-rate conditions. 
- Increasing the inclined angle and decreasing the number of parallel channels are favorable for more uniform flow distribution. However, the compactness of the network may then be lost.

334 It should be noted that both models could provide relatively uniform flow distribution under very low

335 flow-rate conditions. The potential applications could be for fuel cells where the flow velocity in 336 parallel channel is small, with the aim of process intensification. Another direction of application is to 337 construct a multi-scale fluidic network such as shown in Figure 1a, so that the working load for each 338 elemental Z-type circuit could be relatively small.

339 Our ongoing works are focused on the development of more appropriate scaling relations and 340 evolutionary algorithms (Wang et al., 2010; 2014; Luo et al., 2015) for more subtle modifications of 341 the distributor/collector shape, in order to reach uniform flow distribution with small increase of 342 pressure loss. Numerical and experimental investigations on the hydraulic and thermal characteristics 343 of a multi-scale ladder network are also the directions of our future work.

\section{ACKNOWLEDGEMENT}

346 The authors would like to thank the "Region Pays de la Loire" for the project "Nouvelle équipe de 347 recherche" and its financial support to the PhD study of M. Cyril Pistoresi.

\section{NOMENCLATURE}

$350 \quad D_{h} \quad$ Hydraulic diameter [m]

$351 e \quad$ Thickness of the fluidic network [m]

$352 q \quad$ Volume flow-rate $\left[\mathrm{m}^{3} \cdot \mathrm{s}^{-1}\right]$

$353 \quad \bar{q} \quad$ Mean flow rate among mini-channels $\left[\mathrm{m}^{3} \cdot \mathrm{s}^{-1}\right]$

$354 \quad f \quad$ Friction factor $[-]$

$355 \quad F \quad$ Form factor $[-]$

$356 \quad \vec{F} \quad$ External body force $\left[\mathrm{kg} \cdot \mathrm{m} . \mathrm{s}^{-2}\right]$

$357 g \quad$ Gravitational acceleration $\left[\mathrm{m} \cdot \mathrm{s}^{-2}\right]$ 
$358 \quad I \quad$ Unit tensor [-]

$359 l_{x} \quad$ Space between two mini-channels [m]

$360 \quad L \quad$ Length [m]

361 MF Maldistribution factor [-]

$362 N \quad$ Number of parallel mini-channels [-]

$363 p \quad$ Static pressure $[\mathrm{Pa}]$

$364 \quad R \quad$ Hydraulic resistance [Pa.s.m ${ }^{-3}$ ]

$365 \quad \operatorname{Re} \quad$ Reynolds number [-]

$366 \quad \vec{u} \quad$ Velocity $\left[\mathrm{m} \cdot \mathrm{s}^{-1}\right]$

$367 U_{\text {in }} \quad$ Velocity at the inlet of the network $\left[\mathrm{m} \cdot \mathrm{s}^{-1}\right]$

$368 \quad w \quad$ Width [m]

369

370 Greek symbols

$371 \Delta p \quad$ Pressure loss $[\mathrm{Pa}]$

$372 \theta \quad$ Angle of Distributor/Collector pipes $\left[{ }^{\circ}\right]$

$373 \mu \quad$ Viscosity $\left[\mathrm{kg} \cdot \mathrm{m}^{-1} \cdot \mathrm{s}^{-1}\right]$

$374 \Pi \Pi \quad$ Stress tensor [-]

$375 \rho \quad$ Density of the fluid $\left[\mathrm{kg} \cdot \mathrm{m}^{-3}\right]$

$376 \sigma \quad$ Relative flow-rate deviation [-]

377

378 Subscripts

$379 \quad c \quad$ Collector pipe

380 ch Mini-channel

$381 \quad d \quad$ Distributor pipe

382 in Inlet

$383 \quad k \quad$ Channel index

384 out Outlet 


\section{REFERENCES}

387

Al-Rawashdeh, M., Yu, F., Nijhuis, T.A., Rebrov, E.V., Hessel, V., Schouten, J.C., 2012, Numberedup gas-liquid micro/milli channels reactor with modular flow distributor, Chemical Engineering Journal, 207-208, 645-655

Anxionnaz, Z., Cabassud, M., Gourdon, C., Tochon, P., 2008, Heat exchanger/reactors (HEX reactors): Concepts, technologies: State-of-the-art, Chemical Engineering and Processing: Process Intensification, 47, 2029-2050

Cho, E.S., Choi, J.W., Yoon, J.S., Kim, M.S., 2010, Modeling and simulation on the mass flow distribuion in microchannel heat sinks with non-uniform heat flux conditions, International journal of Heat and Mass Transfer, 53, 1341-1348

Charpentier J.C., 2005, Process intensification by miniaturization, Chemical Engineering Technology, $28,255-258$

Commenge, J.-M., Falk, L., 2014, Methodological framework for choice of intensified equipment and development of innovative technologies, Chemical Engineering and Processing: Process Intensification, 84, 109-127

Commenge, J.-M., Falk, L., Corriou, J.P., Matlosz, M., 2002, Optimal design for flow uniformity in microchannel reactors, AIChE Journal, 48 345-358

Commenge, J.-M., Saber, M., Falk, L., 2011, Methodology for multi-scale design of isothermal laminar flow networks, Chemical Engineering Journal, 173, 541-551

Fan, Y., Luo, L., 2008, Recent applications of advances in microchannel heat exchangers and multiscale design optimization, Heat Transfer Engineering, 29, 461-474

Fan, Y., Boichot, R., Goldin, T., Luo, L., 2008, Flow distribution property of the constructal distributor and heat transfer intensification in a mini heat exchanger, AIChE Journal, 54, 27962808.

Guo, X., Fan, Y., Luo, L., 2013, Mixing performance assessment of a multi-channel mini heat exchanger reactor with arborescent distributor and collector, Chemical Engineering Journal, 227, 116-127 
Guo, X., Fan, Y., Luo, L., 2014, Multi-channel heat exchanger-reactor using arborescent distributors:

414 A characterization study of fluid distribution, heat exchange performance and exothermic reaction, Energy, 69, 728-741

Hessel, V., Löwe, H., Schönfeld, F., 2005, Micromixers-a review on passive and active mixing principles, Chemical Engineering Science, 60, 2479-2501

Illg, T., Löb, P., Hessel, V., 2010, Flow chemistry using milli- and microstructured reactors-From conventional to novel process windows, Bioorganic \& Medicinal Chemistry, 18, 3707-3719

Jackson, J.M., Hupert, M.L., Soper, S.A., 2014, Discrete geometry optimization for reducing flow non-uniformity, asymetry, and parasitic minor loss pressure drops in Z-type configurations of fuel cells, Journal of Power Sources, 269, 274-283

Khan, M.G., Fartaj, A., 2011, A review on microchannel heat exchangers and potential applicaions, International journal of energy research, 35, 553-582

Kim, S., Choi, E., Cho, Y.I., The effect of header shapes on the flow distribution in a manifold for electronic packaging applications, International Communications in Heat and Mass Transfer, 22, $329-341$

Luo, L., 2013, Heat \& Mass Transfer Intensification and Shape Optimization: A Multi-scale Approach, Springer.

Luo, L., Fan, Y., Tondeur, D., 2007. Heat exchanger: from micro to multi-scale design optimization, International Journal of Energy Research, 31, 1266-1274

Luo, L., Wei, M., Fan, Y., Flamant, G., 2015, Heuristic shape of optimization of baffled fluid distributor for uniform flow distribution, Chemical Engineering Science, 123, 542-556

Midoux, N., Tondeur, D., 2014, The theory of parallel channels manifolds (Ladder networks) Revisited Part 1: Discrete mesoscopic modelling. The Canadian Journal of Chemical Engineering, 92, 1798-1821.

Midoux, N., Tondeur, D., 2015, The theory of parallel channels manifolds (Ladder networks) Revisited Part 2: Design for uniform cross-flow distribution. The Canadian Journal of Chemical Engineering, 93, 121-140. 
Pan, M., Tang, Y., Pan, L., Lu, L., 2008, Optimal design of complex manifold geometries for uniform flow distribution between micochannels, Chemical Engineering Journal, 137, 339-346

Pan, M., Zeng, D., Tang, Y., Chen, D., 2009, CFD-based study of velocity distribution among multiple parallel microchannels, Journal of Computers, 4, 1133-1138

Renault, C., Roche, J., Ciumag, M.R., Tzedakis, T., Colin, S., Serrano, K., Reynes, O., André-Barrès, C., Winterton, P., 2012, Design and optimization of electrochemical microreactors for continuous electrosynthesis, Journal of Applied Electrochemistry, 42, 667-677

Rebrov, E.V., Schouten, J.C., De Croon, M.H.J.M., 2011, Single-phase fluid flow distribution and heat transfer in microstructured reactors. Chemical Engineering Science, 66, 1374-1393

Saber, M., Commenge, J.-M., Falk, L., 2009, Rapid design of channel multi-scale networks with minimum flow maldistribution, Chemical Engineering and Processing: Process Intensification, $48,723-733$

Saber, M., Commenge, J.-M., Falk, L., 2010, Microreactor numbering-up in multi-scale networks for industrial-scale applications: Impact of flow maldistribution on the reactor performances, Chemical Engineering Science, 65, 372-379

Stankiewicz, A., Moulijn, J.A., 2002, Process Intensification, Industrial \& Engineering Chemistry Research, 41, 1920-1924

Sung, Y., 2006, Optimization of a fuel-cell manifold, Journal of Power Sources, 157, 395-400

Tondeur, D., Fan, Y., Commenge, J-M., Luo, L., 2011a, Flow and pressure distribution in linear discrete "ladder-type" fluidic circuits: An analytical approach, Chemical Engineering Science, 66, $2568-2586$

Tondeur, D., Fan, Y., Commenge, J-M., Luo, L., 2011b, Uniform flows in rectangular lattice networks, Chemical Engineering Science, 66, 5301-5312

White, F.M., 2003, Fluid Mechanics, 5th Edition, McGraw-Hill.

Wang, L., Fan, Y., Luo, L., 2010, Heuristic optimality criterion algorithm for shape design of fluid flow, Journal of Computational Physics, 229, 8031-8044

Wang, L., Fan, Y., Luo, L., 2014, Lattice Boltzmann method for shape optimization of fluid distributor, Computers \& Fluids, 94, 49-5 